\title{
A group-based real-time videoconferencing telerehabilitation programme in recently discharged geriatric patients: a feasibility study
}

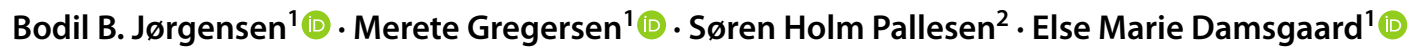

Received: 18 August 2020 / Accepted: 17 December 2020 / Published online: 5 February 2021

(c) European Geriatric Medicine Society 2021

\section{Key summary points}

Aim To examine the feasibility of conducting videoconferencing telerehabilitation in groups of a geriatric population recently discharged from hospital.

Findings Telerehabilitation recently after an acute hospitalisation was not feasible in a geriatric population.

Message Aspects such as recruitment procedures and IT solutions designed for older people must be considered in geriatric patients.

\begin{abstract}
Purpose Exercise at home and improvement in the ability to undertake daily tasks are highly valued by older people after hospitalisation. New telerehabilitation (TR) technologies make it possible to supervise and communicate with exercising participants through videoconferencing equipment. This technology has been shown to be both feasible and effective in Danish chronic obstructive pulmonary disease patients in terms of basic mobility, safety, social interactions and patient perception. This study sought to examine whether it was feasible to carry out TR through home exercises in groups.

Methods Both medical and hip-fracture home-dwelling patients aged 65 years and older admitted to the Emergency Department (ED) and Department of Geriatrics for acute reasons were asked to participate in the study just before their discharge. The inclusion criteria were normal cognitive function, being dependent on a walking aid and computer users before hospitalisation. Results At discharge, 333 patients were consecutively screened for participation. Of those, 300 patients were excluded. Thirtythree patients met the inclusion criteria. They had a mean age of 82.3 years $( \pm 7.8)$ and $76 \%$ were women. Nine patients agreed to participate, but seven withdrew. The most frequent explanation was exhaustion in the continuation of hospitalisation.

Conclusion It was not possible to conduct a videoconference TR study in a geriatric population, as many were excluded and those who were eligible withdrew after inclusion. During the COVID-19 pandemic, TR may be an important tool for isolated older persons to hinder functional decline. Aspects such as recruitment procedures and IT solutions designed for older people must be considered.
\end{abstract}

Bodil B. Jørgensen

bodijoer@rm.dk

Merete Gregersen

meregreg@rm.dk

Søren Holm Pallesen

sohp@aarhus.dk

Else Marie Damsgaard

elsedams@rm.dk

1 Department of Geriatrics, Aarhus University Hospital, Palle Juul-Jensens, Boulevard 99, 8200 Aarhus N, Denmark

2 Center for Assisted Living Technology, Municipality of Aarhus, Aarhus, Denmark 
Keywords Group based telerehabilitation · Acute patients $\cdot$ Recruitement procedures $\cdot$ Exhaustion $\cdot$ Computer familiarity

\section{Background}

Telerehabilitation (TR) is widely employed using a great number of technologies in different rehabilitation settings and among various age populations. TR is defined as the delivery of rehabilitation using telecommunication technologies [1-5]. Conducted via real-time videoconferencing, TR requires basic computer skills and access to the internet [2]. In 2019, more than half of the world's population were internet users. However, due to differences in the countries' infrastructure, access to the internet is not equally present [6]. When we look at the countries in Europe, there are still big differences in how many inhabitants of the individual countries have never been online, from $32 \%$ in Kosovo to $1 \%$ in Iceland and Norway [7]. The proportion increases steadily with age. Worldwide, only $7 \%$ aged 65 years and up are connected to the internet [8]. Among older persons in the United States, technological solutions are not a natural choice. Forty-four percent of seniors aged 80 or older report using the internet, but only $28 \%$ have home broadband service [9]. The same pattern is seen in Denmark. Only half of the population states that they feel comfortable meeting the demands of the internet and computer use, and $10 \%$ of persons aged 75- 89-year-old report feeling this way [10].

Recruiting patients to a TR intervention can be challenging for various reasons, including impaired cognitive ability, vision and hearing [4]. Videoconferencing TR is a method that enables the participant to exercise in the comfort of their home while maintaining real-time supervision by a physiotherapist [2]. It has been utilised with patients with various diagnoses, and it does not appear inferior to usual rehabilitation programmes $[2,3,11]$. TR may even promote greater adherence to the rehabilitation sessions $[2,11]$. Due to the current COVID-19 situation and the recommended isolation of senior citizens, videoconferencing TR may be a useful second-line alternative to traditional forms of training [12].

During hospitalisation, impaired gait function is observed in almost two-thirds of geriatric patients. Half are dependent on a walking aid, and approximately $16 \%$ have no walking function [13]. In a study by Pedersen et al., ambulatory older medical patients spend $17 \mathrm{~h}$ per day of their hospital time in bed as a median value [14]. This may explain why one-third of medical patients discharged after an acute hospitalisation experience a decrease in functional capacity 1 year later [15]. It seems appropriate, therefore, to start exercises immediately following hospitalisation [16, 17]. The Otago Exercises Programme (OEP) is a home-based rehabilitation programme suitable for older persons. The programme combines exercises of strength, balance and endurance. The participants can conduct the OEP with only a minor risk of falling $[18,19]$. Clinical guidelines recommend that geriatric patients should exercise for at least eight consecutive weeks if clinical benefits may be expected [20]. Therefore, combining videoconferencing equipment with OEP may enable us to deliver TR at home to geriatric patients. Thus, the aim of this study was to examine whether groupbased TR conducted via a real-time videoconference system is feasible for geriatric patients recently discharged form a geriatric department after acute hospitalisation.

\section{Materials and methods}

The first study period was from 15 March to 16 May 2018, which included only older medical patients. Hoping to achieve greater inclusion, we chose to try again; in this period, we also included older hip-fracture patients in the TR study. The next period ran from 1 September to 8 November 2018.

\section{Design}

This feasibility study describes the recruitment process and explores the practicality of offering TR to geriatric patients recently discharged from hospital after acute illness. Quantitatively, we counted the number of patients eligible for the study, the number of patients who agreed to participate and the number of patients who dropped out gradually. Simultaneously, eligible patients were interviewed according to a qualitatively structured interview form to identify challenges and barriers to conducting TR at home.

\section{Population and setting}

The patients were residents living in their own homes. They were admitted to the ED and Department of Geriatrics of Aarhus University Hospital (AUH) due to acute illness. In total, AUH has a 1150-bed capacity. Besides the outpatient clinic and fall clinic, the Department of Geriatrics consists of two geriatric wards containing 32 beds in total. In a study, where 1467 patients were included from 1 January 2018, to 1 October 2019, geriatric patients discharged from the two geriatric wards were assessed: $8 \%$ were considered non-frail, $43 \%$ moderately frail and $49 \%$ severely frail [17]. The relevant target group to be part of the feasibility study was selected according to the following criteria: aged 65 years or older; medical patients or hip-fracture patients; living in the municipality of Aarhus; dependent on a walking aid at discharge; and computer users, as verified by asking the patients whether they used a computer before hospitalisation. Furthermore, 
they should be able to obtain a stable network, and must provide informed consent. Patients were excluded if they had a terminal illness, were unable to communicate via telephone or computer, were unable to walk independently with a walking aid, were unable to speak or understand Danish, suffered from dementia, had a Short Portable Mental Status Questionnaire (SPMSQ) score above 4, were unable to complete the OEP without a great risk of falling or had suffered from acute stroke [21].

\section{Participant recruitment procedure}

The identification of patients who met the eligibility criteria was performed on weekdays at the hospital by the project manager of this feasibility study. Patients discharged directly from the ED on weekends or on public holidays were assessed for their eligibility on the first following weekday.

\section{IT platform}

The KMD Viva platform was developed to be used with a real-time videoconference system. The system made it possible for the physiotherapists supervising the OEP, to follow the whole group of patients on the same screen and communicate with the participants individually. The participants were also able to watch the physiotherapist on their own screens and to communicate with each other.

\section{Access to the internet}

It was not a requirement that the participants had installed a particular network. Instead, we connected a dongle to the participant's computer to obtain an internet connection.

\section{Interventions}

The intervention was planned to start within the first week after the participant's discharge. The participants were intended to receive supervised TR by an experienced physiotherapist 3 days per week during a 4-week period (12 sessions in total), with at least 1 day of rest between each exercise session. For those who agreed to participate, the physiotherapist initially visited the patient at home. The patient was informed about the exercise program, orally and by a written pamphlet, as well as about the benefits of exercising and the expected effect of the programme. Subsequently, a computer was set up, where the participant and physiotherapist had decided that exercise should be practised. The computers were installed with webcams and microphones, making it possible for the participants to see and communicate with the physiotherapist and other participants during the sessions. Participants were also provided with a booklet and a face-to-face education session on how to use the equipment. As the computer was being installed, the participant was introduced to the OEP. If there were any technical problems, it was occasionally necessary to visit the participant again. The OEP takes approximately $30 \mathrm{~min}$ to complete. Initially, it was expected that the participants may need pauses between the exercises, so three-quarters of an hour were allocated to each exercise session [22]. The first two training sessions were individually adjusted to allow the participants to become confident using the computer programme and to ensure that it was functioning correctly, with the participant able to hear the physiotherapist and see the instructions on the screen. When four participants had been introduced to the group after the individual training sessions, we stopped accepting new participants and the group completed the OEP for 4 weeks with supervising from the physiotherapist. Over the following 4 weeks, the participants were intended to exercise without the physiotherapist's supervision in group training sessions that continued at appointed times. The participants were still able to see and communicate with the other participants over the computer. The OEP was displayed on the computer during video sessions. Twice a week, the physiotherapists contacted the participants over their computers to check that there were no problems regarding the exercise sessions. Following the National Clinical Guidelines for the nutrition and training of elderly people with geriatric problems, the participants were encouraged to drink protein supplements immediately after the OEP training sessions to optimise the effect of the intervention [20].

\section{Data collection}

Data were collected by a therapist skilled in administering tests and conducting interviews. The number of patients referred to the Department of Geriatrics in the two periods for inclusion was recorded. The eligible patients' reasons for refusing TR intervention were registered. Data were collected at admission from the Electronic Patient Record (EPJ) and by interviews about age; sex; social status; weight; educational level; smoking; alcohol consumption; information on the number of hours of home help; and nutrition as measured by the Mini Nutritional Assessment (MNA) [23]. Comorbidity was measured by the Cumulative Illness Rating Scale-Geriatrics (CIRS-G) [24] and by medication according to the number of drugs used at admission [25]. Cognitive function was assessed by the Short Portable Mental Status Questionnaire (SPMSQ) [21]. The patients physical functioning and mobility before hospitalization were assessed by Functional Recovery Score (FRS) [26]. Basic mobility during hospitalization was assessed by Cumulated Ambulation 
Score (CAS) [27]. Fitness activities prior to admission were assessed by interview.

\section{Structured interviews}

To avoid losing participants to the interview part, we chose to make the interviews as simple as possible. The interviews were conducted as a structured interview form. The participants were asked identical questions in the same way and order. Therefore, we posed only one question: whether the patients would like to describe 'the challenges and/or barriers to participating in this TR project'. The interviewer was a neutral facilitator so the patients could present their experiences in as much detail as possible. This was done by asking 'can you give an example of this'? or 'can you elaborate on what you are telling me'? The interviews were written directly down on a laptop. Next, all interviews were analysed, condensed and separated into specific themes. This combination strengthens the study, which also achieved theoretical saturation, as expressed by respondents' repeated answers already mentioned by previous respondents [28, 29]. The interviews were conducted either in the patient's single-bed room at the hospital, the patient's own home or by telephone.

\section{Statistical analysis}

Comparisons between eligible patients who declined to participate and eligible patients who participated were performed using the independent-samples Student's t-test and Chi-square test, as appropriate.

\section{Compliance with ethical standards}

The study was approved by the Central Denmark Region Committees on Health Research Ethics (1-10-72-394-17) and by the Danish Data Protection Agency (1-16-02-20117). Participants that gave informed consent could withdraw at any time. TR communication between patient and therapist was carried out over the internet using a secure system.

\section{Results}

In total, 333 geriatric patients, including both medical and hip-fracture patients, were referred to the geriatric ward during the two periods. The first period included only medical patients $(n=92)$, and the second period included both medical and hip-fracture patients $(n=241)$. Of the 333 patients, 33 were eligible to participate, but 24 declined. This resulted in nine persons who agreed to participate, but only two patients were enrolled in the study as seven withdrew from the study before starting the training sessions (Fig. 1).
The eligible patients $(n=33)$ had a mean age of 82.3 years $( \pm 7.8)$ and $76 \%$ were female. No difference in characteristics were found between the nine patients who agreed to participate and the 24 eligible patients who declined due to low functional capacity, social status, educational level and frailty. There were significantly more men in the group who agreed to participate compared to those who declined to participate $(p=0.05)$.

The most frequent reason for exclusion was reduced cognition (35\%). Patients who had no gait function comprised $13 \%$ of the reasons for exclusion. Being able to see the computer screen was also a prerequisite for participating in our TR intervention. Thirteen percent of the considered patients either had very low vision or were completely blind.

\section{Challenges and barriers}

Seventeen patients out the 33 patients were interviewed. The interviewed patients had a mean age of 79 years. Three of the respondents were patients who initially agreed to participate and later dropped out. During the interviews, the eligible but non-participating patients described different reasons for their refusal. Some declined to participate when asked at the hospital and others after discharge despite having given informed consent during hospital admission.

\section{Feeling exhausted}

The most frequent explanation for refusal to participate was exhaustion. One patient who first agreed to participate and then withdrew described the period after discharge as very exhausting, saying: 'I did not have the energy, and I got a stomach infection the first week after discharge. Maybe if the offer of training was a few weeks later, I might have agreed to continue in the project'. Another patient had an almost identical explanation with stomach infection following hospitalisation. The time for starting up TR was too close to their discharge. Both chose a few weeks after the traditional offer in the municipality (Table 1).

\section{Not feeling familiar}

The next most frequent reason for refusal was that although the patients had a computer installed at home, they did not feel familiar enough to use it for a project. One patient stated that 'I really want to join, but I'm not an expert at IT, so I'm afraid it gets too complicated for me'. Another patient said, 'I'm not so good at using a computer. It's more my husband. I have used it very little; it has very little interest. I am joining a training center together with a friend. So I want to continue the training I attended before my hospitalization'. 

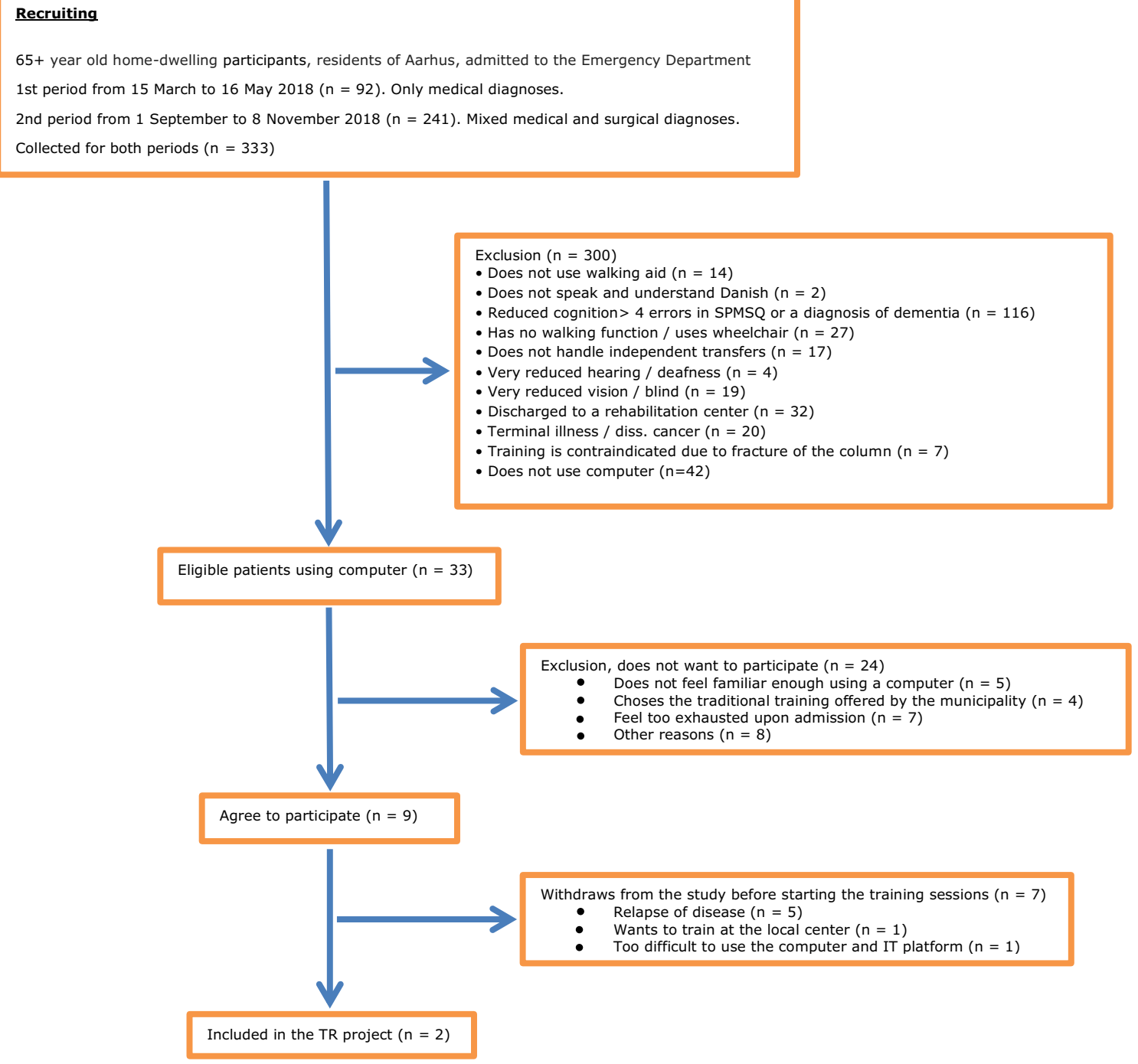

Fig. 1 Flowchart of patient selection for the feasibility study

\section{Choosing the traditional training offer}

As the quotation above suggest, another frequent explanation for not participating was that the patients chose the traditional training offer in the community support center for older people. One patient declined to participate, saying 'I use the computer very little and do not feel comfortable using it. In addition, I think it seems strange to receive exercises in front of a computer. My son said I should use the local gym. He thinks it's best for me. Moreover, I also have two fractures to deal with'.

\section{Other reasons for not participating}

One patient refused to attend the TR intervention because he did not have enough space in his apartment to perform the exercises. Another patient undergoing surgery for a hipfracture had to stay with her daughter for the first few weeks after discharge and believed that participating would cause too much hassle when the sessions did not take place in her own home. Another patient did not feel that he belonged to the target group and found it difficult to set aside time to exercise more frequently each week at scheduled times.

\section{Discussion}

TR immediately after hospital discharge was found unfeasible in a geriatric population hospitalised due to acute illness. To our knowledge, only one pilot study by Peel et al. examined TR in geriatric patients just discharged after acute illness, and they found comparable challenges. They investigated among other topics the feasibility of rehabilitation 
Table 1 Factors influencing deselection of telerehabilitation in geriatric patients

\begin{tabular}{|c|c|c|c|c|}
\hline Sex (age) & $\begin{array}{l}\text { Are PC users but does not feel } \\
\text { familiar with the application }\end{array}$ & $\begin{array}{l}\text { Chooses traditional } \\
\text { training offer }\end{array}$ & $\begin{array}{l}\text { Was too exhausted to deal with new ini- } \\
\text { tiatives following the hospitalisation }\end{array}$ & $\begin{array}{l}\text { Not able to express } \\
\text { an exact reason/other } \\
\text { reasons }\end{array}$ \\
\hline Woman (90) & & & & $\mathrm{x}$ \\
\hline Woman (73) & $\mathrm{x}$ & $\mathrm{x}$ & & \\
\hline Woman (70) & & & $\mathrm{x}$ & \\
\hline Man (75) & & & & $\mathrm{x}$ \\
\hline Woman (80) & $\mathrm{x}$ & & & \\
\hline Woman (85) & $\mathrm{x}$ & & & \\
\hline Woman (80) & & & $\mathrm{x}$ & \\
\hline $\operatorname{Man}(81)$ & & & & $\mathrm{x}$ \\
\hline Woman (65) & & $\mathrm{x}$ & $\mathrm{x}$ & \\
\hline Woman (87) & $\mathrm{x}$ & & & \\
\hline Man (69) & & $\mathrm{x}$ & & \\
\hline Woman (75) & $\mathrm{x}$ & & & \\
\hline Woman (81) & & & $\mathrm{x}$ & \\
\hline Woman (80) & & $\mathrm{x}$ & $\mathrm{x}$ & \\
\hline Woman (86) & & & $\mathrm{x}$ & \\
\hline Woman (78) & & & $\mathrm{x}$ & \\
\hline Woman (79) & $\mathrm{x}$ & & & \\
\hline
\end{tabular}

services offered remotely via physical consultations conducted by physiotherapist, occupational therapists, and speech pathologists through an in-home videoconferencing system to geriatric patients [4]. In Peel et al.'s study, patients were at risk of readmission or transfer to a nursing home. The study period ran for 8 months, and all 44 patients were assessed for eligibility; almost half of the patients were ineligible due to hearing and/or vision impairment. Factors such as anxiety, stress, dementia and a cluttered home environment were other reasons for inability to participate. Ten patients were considered eligible, but three declined to participate in the study, preferring real-time face-to-face assessment. The study continued with three patients, one of whom became more ill and bedbound after enrolment. The study concluded the TR programme was more suitable for patients with fewer comorbidities and higher levels of mobility [4].

In a study by Smaerup et al., TR was found feasible in older persons from a fall clinic. The participants were outpatients, in better general condition, younger and likely more familiar with computers and the internet than those in our study [30]. This supports the hypothesis that the youngest age group of older persons more readily sign up for TR studies, as they are likely more familiar with using computers and the internet [2]. In a study by van Dam van Isselt it was also feasible to recruit geriatric patients with cardiovascular diseases (CVDs) to a rehabilitation programme, perhaps because the patients remained hospitalised, and they did not have to be trained in any kind of technology that requires good cognitive, visual and aural functions [31].
In patients with depression or CVD, Foster et al. investigated which persons did not participate in TR and why. More than half declined to participate due to lack of access to the internet. Technology reasons were more prevalent in older patients in the depression group, verified by a 15-year difference between those who declined for technology reasons and those willing to participate [32].

In the current study, we were challenged by patients who preferred traditional training offers to TR. Hansen et al., who investigated TR videoconferencing in groups with a population with Chronic Obstructive Pulmonary Disease (COPD), also faced this change, as $65 \%$ of the eligible patients chose the conventional training offer [16].

Brouns et al. found that a TR programme should be accessible on multiple devices, such as a computer, laptop, tablet or a smartphone, and they concluded it is crucial that the patient be comfortable with the device [33]. In our study, the devices were limited to a computer with a 21-inch screen because the screen display was divided into the number of participants, meaning that the screen became smaller with more participants. For this reason, we chose to include a maximum of four participants. The IT platform used required certain basic computer skills. Although the participants were trained in using the platform and brochures were handed out at the same time, some challenges arose. For example, we tried to train a participant to use a mouse without success. Another participant stated that she had attended an evening school to learn how to use a computer mouse. Murata et al. likewise found that using a mouse took longer 
for older people than for younger people, as opposed to using a touch screen [34]. For a real-time TR study with community-dwelling older adults with a mean age of 82 years, Hong et al. developed an elder-friendly website and used a computer with a touch screen, which they described as relatively simple and accessible technology for older people to use [35]. Peretti et al. also indicated the need for further research to improve electronic devices and equipment and make their applications as flexible as possible [36]. Facing the difficulties in using a computer and a computer mouse, were some of the reasons why we changed inclusion criteria from 75 to 65 years. An explanation for Damhus et al.'s success in recruiting participants to their TR trial may be that the participants have a relatively young mean age of $68( \pm 9)$ years and thereby might be more familiar with computers and the internet than older people $[2,16]$.

In the present study, we found two dominant challenges: time for recruitment and computer skills. Patients were fatigued following their illness and hospitalisation. Some described their time after discharge as chaotic and reported often feeling exhausted. Some had started receiving home care for the first time, which meant many new people visiting their home, sometimes multiple times a day. Some could not cope with a new initiative immediately following hospitalisation. This may have affected their decision to decline participation in this study when they were asked during their hospitalisation. It may also have affected those few patients who initially agreed to participate but dropped out after discharge. Exhaustion more or less existed in all the geriatric patients at the time we chose for the recruitment to take place. Even though exhaustion was not always the primary reason for deselecting TR, the choice of the traditional training offer in the municipality could also be due to lack of energy. The same goes for those who said that they did not feel familiar enough with using a computer. It again required extra energy to learn new features on their computer to access the used IT platform. The development of a computer and IT platform that are user-friendly for older people is crucial.

Now, during the COVID-19 pandemic, researchers are developing a real-life videoconferencing system through which relatives or health professionals can communicate with, for example, older persons via their television. The person initiating the contact uses a computer link, while the older, contacted person's television turns on automatically; both can instantly see and communicate with each other. This system only requires the older person to have an external webcam and access to the internet. The system also makes it possible to gather more people, e.g., to group exercise sessions via the same link. All communication takes place within a secure closed system [37].

In a geriatric population, it may be advisable not to start TR immediately following the older patient's discharge from hospital. However, supervised exercise in the older person's own home is important to recover after acute illness. When ready, the older person could be offered TR individually or in groups.

In conclusion, this feasibility study examined real-time videoconferencing TR with a geriatric population immediately following discharge from hospitalisation. Lack of sufficient computer skills and exhaustion after acute illness were identified as two major challenges. Therefore, there is a need to develop easy-access IT solutions for older persons to support TR and address how soon after discharge the acute geriatric patient is able to participate in TR.

Acknowledgements The authors would like to thank the patients involved for their contributions to either the interviews or their feedback on how telerehabilitation equipment can be optimized for future studies. Also a thank you to the staff involved in the Department of Geriatrics for their participation in this study. A special thank to the Municipality of Aarhus with good feedback on how telerehabilitation can be implemented in a municipal setting.

Funding This study did not receive any grants.

\section{Compliance with ethical standards}

Conflict of interest On behalf of all authors, the corresponding author declare that there is no competing interest.

Ethical approval The study was approved by the Research Ethics Committee of the Central Denmark Region (1-10-72-394-17) and by the Danish Data Protection Agency (1-16-02-201-17). Participants were informed that participation was voluntary and that they could withdraw at any time.

Informed consent Individuals who agreed to participate gave informed consent. Information about the study was given to ensure that all aspects of the study were understood.

\section{References}

1. Dithmer M, Rasmussen JO, Gronvall E, Spindler H, Hansen J, Nielsen G et al (2016) "The Heart Game": using gamification as part of a telerehabilitation program for heart patients. Games Health J 5(1):27-33

2. Hansen H, Bieler T, Beyer N, Kallemose T, Wilcke JT, Østergaard LM et al (2020) Supervised pulmonary tele-rehabilitation versus pulmonary rehabilitation in severe COPD: a randomised multicentre trial. Thorax 75(5):413-421

3. Hwang R, Bruning J, Morris NR, Mandrusiak A, Russell T (2017) Home-based telerehabilitation is not inferior to a centre-based program in patients with chronic heart failure: a randomised trial. J Physiother 63(2):101-107

4. Peel NM, Russell TG, Gray LC (2011) Feasibility of using an in-home video conferencing system in geriatric rehabilitation. $\mathrm{J}$ Rehabil Med 43(4):364-366

5. Russell TG, Buttrum P, Wootton R, Jull GA (2011) Internet-based outpatient telerehabilitation for patients following total knee arthroplasty: a randomized controlled trial. J Bone Joint Surg Am Vol 93(2):113-120 
6. Statista J (2020) Clement. Internet usage worldwide-statistics \& facts. Hamburg. https://www.statista.com/statistics/273018/numbe r-of-internet-users-worldwide/. Accessed 10 Nov 2020

7. Eurostat tsootEU (2017) Individuals-computer use. Luxembourg. https://ec.europa.eu/eurostat/databrowser/view/isoc_ci_ cfp_cu/default/table?lang=en. Accessed 14 Jun 2017

8. Statista J (2019) Clement. Internet user by age worldwide. https ://www.statista.com/statistics/272365/age-distribution-of-inter net-users-worldwide/. Accessed 01 Dec 2020

9. Pew Research Center IaT (2017) Technology use among seniors. https://www.pewresearch.org/internet/2017/05/17/technology -use-among-seniors/. Accessed 17 May 2020

10. Tassy A, Nielsen MB, Jakobsen DT (2018) It-anvendelse i befolkningen 2017, Danmarks Statistik. https://www.dst.dk/Site/Dst/ Udgivelser/GetPubFile.aspx?id=20739\&sid=itbef2017. Accessed 09 May 2018

11. Chen J, Jin W, Dong WS, Jin Y, Qiao FL, Zhou YF et al (2017) Effects of home-based telesupervising rehabilitation on physical function for stroke survivors with hemiplegia: a randomized controlled trial. Am J Phys Med Rehabil 96(3):152-160

12. Goethals L, Barth N, Guyot J, Hupin D, Celarier T, Bongue B (2020) Impact of home quarantine on physical activity among older adults living at home during the COVID-19 pandemic qualitative interview study, p e19007. Toronto, ON: JMIR Publications Inc.

13. Pedersen LH, Gregersen M, Barat I, Damsgaard EM (2016) Early geriatric follow-up after discharge reduces readmissions. A quasirandomised controlled trial. Eur Geriatr Med 7(5):443-448. https ://doi.org/10.1016/j.eurger.2016.03.009

14. Pedersen MM, Bodilsen AC, Petersen J, Beyer N, Andersen O, Lawson-Smith L et al (2013) Twenty-four-hour mobility during acute hospitalization in older medical patients. J Gerontol Ser A Biol Sci Med Sci 68(3):331-337

15. Buurman BM, Hoogerduijn JG, de Haan RJ, Abu-Hanna A, Lagaay AM, Verhaar HJ et al (2011) Geriatric conditions in acutely hospitalized older patients: prevalence and one-year survival and functional decline. PLoS ONE 6(11):e26951

16. Damhus CS, Emme C, Hansen H (2018) Barriers and enablers of COPD telerehabilitation - a frontline staff perspective. Int J Chron Obstruct Pulmon Dis 13:2473-2482

17. Gregersen M, Hansen TK, Jørgensen BB, Damsgaard EM (2020) Frailty is associated with hospital readmission in geriatric patients: a prognostic study. Eur Geriatr Med. https://doi. org/10.1007/s41999-020-00335-w

18. Benavent-Caballer V, Rosado-Calatayud P, Segura-Orti E, AmerCuenca JJ, Lison JF (2016) The effectiveness of a video-supported group-based Otago exercise programme on physical performance in community-dwelling older adults: a preliminary study. Physiotherapy 102(3):280-286

19. Campbell AJ, Robertson MC, Gardner MM, Norton RN, Tilyard MW, Buchner DM (1997) Randomised controlled trial of a general practice programme of home based exercise to prevent falls in elderly women. BMJ 315(7115):1065-1069

20. Sundhedsstyrelsen. National Klinisk Retningslinje for ernæringsog træningsindsatser til ældre med geriatriske problemstillinger. 2016. https://www.sst.dk/da/udgivelser/2016/ /media/316C3 E23E56D4F2DB7BF9C14A70F364D.ashx. Accessed Web Page 2016

21. Erkinjuntti T, Sulkava R, Wikstrom J, Autio L (1987) Short portable mental status questionnaire as a screening test for dementia and delirium among the elderly. J Am Geriatr Soc 35(5):412-416
22. Campbell AJ, Robertson MC. Otago Exercise Programme, to prevent falls in older adults. 2007. https://www.livestronger.org. nz/assets/Uploads/acc1162-otago-exercise-manual.pdf Accessed Web Page 2007

23. Guigoz Y, Lauque S, Vellas BJ (2002) Identifying the elderly at risk for malnutrition. The mini nutritional assessment. Clin Geriatr Med 18(4):737-757

24. Miller MD, Paradis CF, Houck PR, Mazumdar S, Stack JA, Rifai $\mathrm{AH}$ et al (1992) Rating chronic medical illness burden in geropsychiatric practice and research: application of the Cumulative Illness Rating Scale. Psychiatry Res 41(3):237-248

25. Pilotto A, Ferrucci L, Franceschi M, D'Ambrosio LP, Scarcelli C, Cascavilla L et al (2008) Development and validation of a multidimensional prognostic index for one-year mortality from comprehensive geriatric assessment in hospitalized older patients. Rejuvenation Res 11(1):151-161

26. Zuckerman JD, Koval KJ, Aharonoff GB, Skovron ML (2000) A functional recovery score for elderly hip fracture patients: II. Validity and reliability. J Orthop Trauma 14(1):26-30

27. Kristensen MT, Andersen L, Bech-Jensen R, Moos M, Hovmand B, Ekdahl C et al (2009) High intertester reliability of the cumulated ambulation score for the evaluation of basic mobility in patients with hip fracture. Clin Rehabil 23(12):1116-1123

28. Brinkmann S, Kvale S (2018) Doing interviews. The SAGE qualitative research kit. SAGE, Los Angeles

29. Thienemann MMD (2004) Introducing a structured interview into a clinical setting. J Am Acad Child Adolesc Psychiatry 43(8):1057-1060

30. Smaerup M, Grönvall E, Larsen SB, Laessoe U, Henriksen JJ, Damsgaard EM (2015) Computer-assisted training as a complement in rehabilitation of patients with chronic vestibular dizziness-a randomized controlled trial. Arch Phys Med Rehabil 96(3):395-440

31. Van Dam Van Isselt EF, Van Wijngaarden J, Lok DJA, Achterberg WP (2018) Geriatric rehabilitation in older patients with cardiovascular disease: a feasibility study. Eur Geriatr Med 9(6):853-861

32. Foster A, Horspool KA, Edwards L, Thomas CL, Salisbury C, Montgomery AA et al (2015) Who does not participate in telehealth trials and why? A cross-sectional survey. Trials 16:258

33. Brouns B, Meesters JJL, Wentink MM, de Kloet AJ, Arwert HJ, Vliet Vlieland TPM et al (2018) Why the uptake of eRehabilitation programs in stroke care is so difficult-a focus group study in the Netherlands. Implement Sci IS 13(1):133-018-0827-5.

34. Murata A, Iwase H (2005) Usability of touch-panel interfaces for older adults. Hum Factors 47(4):767-776

35. Hong J, Kong HJ, Yoon HJ (2018) Web-based telepresence exercise program for community-dwelling elderly women with a high risk of falling: randomized controlled trial. JMIR Mhealth Uhealth 6(5):e132

36. Peretti A, Amenta F, Tayebati SK, Nittari G, Mahdi SS (2017) Telerehabilitation: review of the state-of-the-art and areas of application. JMIR Rehabil Assist Technol 4(2):e7

37. Soendergaard M, Kristensen K (2020) Videolink, a real-life videoconferencing system where relatives or health professionals can get in touch with for older persons via their television. https:// careware.dk/p-dage/praesentationsdage/praesentationsdag-naerv aer-paa-afstand-juni-2020/videolink/. Accessed Web Page 2020.

Publisher's Note Springer Nature remains neutral with regard to jurisdictional claims in published maps and institutional affiliations. 